\title{
PERSPECTIVAS PARA O CUIDADO DE ENFERMAGEM ÀS MULHERES QUE DENUNCIAM A VIOLÊNCIA VIVIDA
}

\author{
Perspectives for nursing care to women that report violence experiences \\ Perspectivas para el cuidado de la enfermería a las mujeres que denuncian casos de \\ violencia sufridos
}

\author{
Letícia Becker Vieira ${ }^{1}$ \\ Cristiane Cardoso de Paula ${ }^{4}$
}

Stela Maris de Mello Padoin²

Ívis Emília de Oliveira Souza ${ }^{3}$

\section{RESUMO}

Objetivou-se apresentar perspectivas para o cuidado de enfermagem, a partir da apreensão do significado da ação das mulheres que denunciam a violência vivida. Pesquisa fenomenológica, à luz de Schütz. Cenário: Delegacia de Polícia para Mulher e de Pronto Atendimento de um município do Rio Grande do Sul. Participantes: mulheres de 18-59 anos que realizaram a denúncia da violência do companheiro. Projeto aprovado pelo CEP (n.23081.015518/2009-66). Foram desenvolvidas entrevistas com 13 mulheres. Apreendeu-se que a mulher significa uma relação de anonimato com o companheiro e busca relações de familiaridade para enfrentamento da violência. 0 anonimato acontece pela decisão de romper costumes, sofrimento e história em comum. Quer conduzir a denúncia até o final, acreditar na justiça e proteger/criar seu(s) filho(s). A busca por familiaridade aponta a necessidade de um cuidado de enfermagem a partir da realidade social das mulheres, para reconhecer demandas de saúde e romper a naturalização/aceitação da violência.

Palavras-chave: Enfermagem. Saúde da mulher. Violência contra a mulher.

\begin{abstract}
The objective is to present perspectives to nursing care, from the action meaning apprehension for women who report violence experience. Phenomenological research, in the light of Schütz.Scenary: Women's Police Station and Emergency Department of a district of Rio Grande do Sul. Participants: women from 18-59 years old that reported suffering from domestic violence. Project approved CEP (n.23081.015518/ 2009-66). Interviews were developed with thirteen women. It was learned that women signify an anonymous relationship with partner and seek for familiar relations to cope with violence. Anonymity happens by the decision of breaking habits, suffering and common history. Whether leading the complaint to the end, faith in justice and protect / create their (s) child (ren). Searching for familiarity points to nursing care needs based on women's social reality, in order to recognize health demands and break violence naturalization/acceptance.
\end{abstract}

Keywords: Nursing. Women's health. Violence against women.
Se tiene por objetivo presentar perspectivas para el cuidado de la enfermería, a partir de la aprehensión del significado de la acción de las mujeres que denuncian casos de violencia vividos. Investigación fenomenológica, basada en la teoría de Schütz. Escenario: Jefatura de Policía para Mujer y el Pronto Socorro de un municipio de Rio Grande do Sul. Participantes: mujeres entre 18-59 años, que denunciaron el comportamiento violento del compañero. Proyecto aprobado por el CEP (n.23081.015518/2009-66). Fueron desarrolladas entrevistas con trece mujeres. Se comprendió que la mujer tiene una relación de anonimato con el compañero y busca relaciones de familiaridad para el enfrentamiento de la violencia. El anonimato ocurre por la decisión de romper costumbres, sufrimientos e historias en común. Quiere conducir la denuncia hasta el final, creer en la justicia y proteger/criar su(s) hijo(s). La búsqueda por familiaridad señala la necesidad de un cuidado de enfermería a partir de la realidad social de la mujer para reconocer demandas de salud y romper la naturalización/aceptación de la violencia.

Palabras clave: Enfermería. Salud de la mujer. Violencia contra la mujer.

\footnotetext{
'Enfermeira, Mestre em Enfermagem pelo Programa de Pós-Graduação em Enfermagem UFSM (RS). Doutoranda pela Escola de Enfermagem Anna Nery da Universidade Federal do Rio de Janeiro (RJ). Vice-líder do Núcleo de Estudos sobre Mulheres, Gênero e Políticas Públicas do Departamento de Enfermagem UFSM. Santa Maria - RS. Brasil. E-mail: lebvieira@hotmail.com; ${ }^{2}$ Enfermeira, Doutora em Enfermagem pela Escola de Enfermagem Anna Nery da Universidade Federal do Rio de Janeiro/RJ. Docente no Departamento de Enfermagem - Centro de Ciências da Saúde da Universidade Federal de Santa Maria. Líder do Grupo de Pesquisa Cuidado à Saúde das Pessoas, Famílias e Sociedade - UFSM. Santa Maria-RS. Brasil. E-mail: stelamaris_padoin@hotmail.com; ${ }^{3}$ Enfermeira, Doutora em Enfermagem. Titular de Enfermagem Obstétrica do Departamento de Enfermagem Materno

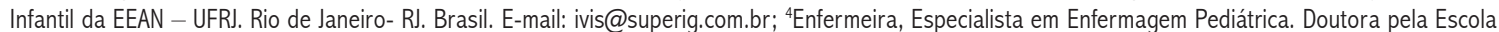
de Enfermagem Anna Nery da Universidade Federal do Rio de Janeiro/RJ. Docente no Departamento de Enfermagem - Centro de Ciências da Saúde da Universidade Federal de Santa Maria. Líder do Grupo de Pesquisa Cuidado à Saúde das Pessoas, Famílias e Sociedade - UFSM. Santa Maria-RS. Brasil. E-mail: cris_depaula1@hotmail.com
} 


\section{INTRODUÇÃO}

Em âmbito mundial, foi na década de 1990 que, oficialmente, o setor saúde começou a assumir a violência, não apenas como uma questão social, mas como de grande importância no campo de pesquisa na área da saúde. Tal valorização ocorreu em decorrência do impacto que provoca na qualidade de vida e pelas lesões físicas, psíquicas e morais que acarreta e pelas exigências de atenção e cuidados dos serviços médico-hospitalares. ${ }^{1}$

Já a violência contra as mulheres assumiu, nas ultimas décadas,um caráter público a partir de reivindicações de movimentos sociais e de mulheres que começaram a denunciar as situações de violência vividas dentro dos lares, que possuía um caráter até então privado, sendo exercida e resolvida entre a mulher e o companheiro, e legitimada por parte da sociedade. Ao ganhar visibilidade e comprovar seus impactos sociais, econômicos e nas questões de saúde dos envolvidos, passaram a ser exigidas, nas agendas governamentais, ações de combate e prevenção da violência no âmbito mundial.?

Embora ao longo dos anos se tenha um movimento por parte da sociedade civil e Estado, com desenvolvimento de convenções, conferências, políticas públicas e legislação que tratam a violência como uma infração legal e uma ação que anula os direitos humanos do segmento feminino, muitas mulheres ainda, em seu mundo da vida cotidiana, convivem e se relacionam com companheiros agressivos, ora em uma atitude de naturalização de tais situações impostas culturalmente pela sociedade, ora buscando meios para romper com o ciclo da violência.

Nesse sentido, buscar um conhecimento acerca da violência contra as mulheres implica desvelar um mundo, a partir de quem a vivencia cotidianamente nas suas relações, mas que até pouco tempo dizia respeito somente à mulher e ao companheiro. Inferir em um espaço visto ainda como íntimo das relações conjugais, mas que as políticas públicas visam combater, por meio de ações conjuntas e dispositivos legais, despertará a necessidade de o cuidado de enfermagem gerar uma orientação mediante o desvelamento, a desnaturalização, o acolhimento e a prevenção de situações vulneráveis nas quais as mulheres são expostas.

A enfermagem caracteriza-se como uma profissão histórica e culturalmente filosófico-humanista, que potencializa a saúde do cidadão e a própria construção da cidadania. Nesse sentido, sua prática não se focaliza apenas no aspecto no biológico, uma vez que a valorização do cuidado, inscrito nas suas diversas formas, pode ainda dar maior visibilidade às injustiças sociais, e o cuidado de enfermagem pode levar à necessidade moral de convivermos com o outro, respeitando sua dignidade e totalidade. ${ }^{3}$ Vislumbra-se, assim, que o cuidado de enfermagem reivindica mais que um elemento objetivo, teórico-científico, já que ele exige a percepção de um componente intersubjetivo capaz de ajudar o cuidador a estabelecer uma ocasião de cuidado empático e autêntico centrado no outro. ${ }^{4}$

Convém mencionar que a enfermagem como prática social possui valores e responsabilidades no orientar suas ações no cuidado que abrangem as questões técnicas, políticas e sociais, de modo que a partir das necessidades dos(as) clientes é que determinamos cuidados de enfermagem de que carecem. ${ }^{5}$ Reitera-se, assim, a importância de captar a realidade social e as necessidades na atitude natural.

Entretanto, o cuidado às mulheres em situação de violência está, muitas vezes, envolto no mundo no qual se valoriza o saber técnico. Este cuidado caracteriza-se como racional, causal e sinônimo de instrumentação, conjunto de procedimentos, de meios e modos de fazer. Contudo, se observa que esse sentido que lhe é atribuído é o vigente, não só em atividades próprias à área da saúde, mas em quaisquer outras atividades humanas. Percebe-se que a influência da técnica no pensamento e no agir humano baseia-se na razão tecnológica. ${ }^{6}$ Desse modo, investigações sobre esse tema podem contribuir com uma visão peculiar da questão da violência e seus desdobramentos na vida das mulheres, sobretudo quando envolve os profissionais de saúde e revela os limites do saber tradicional que se mantêm orientando as práticas profissionais, como saber instrumental, apesar da proposta de um novo modelo de assistência à saúde integral e equânime.?

Ao contextualizar politicamente e legalmente a temática, aponta-se a tentativa do Estado brasileiro de alinhar aos apelos e recomendações internacionais que visam garantir os direitos humanos das mulheres e sua assistência. Dessa forma, o Ministério da Saúde, elaborou em 2004, a "Política Nacional de Atenção Integral à Saúde da Mulher", ${ }^{8}$ que incorpora, na perspectiva de gênero, a integralidade e a promoção da saúde no combate à violência de gênero. Nesta esteira de conquistas políticas, passa-se a dispor desde 0 ano de 2006 de um instrumento legal para prevenção da violência e proteção da mulher. A Lei no 11.340 - Maria da Penha cria mecanismos para coibir a violência doméstica e familiar contra as mulheres, configurando-se como um importante marco de efetivação da política para este segmento. ${ }^{9}$

Aponta-se, assim, a relevância do tema, sua complexidade e a escassez de estudos disponíveis no Brasil que buscam analisar a efetividade de iniciativas governamentais já implementadas de combate à violência contra as mulheres. Nessa direção, são necessários estudos para esclarecer e compreender os mecanismos envolvidos no surgimento e na perpetuação da violência, fornecendo dados que possam embasar estratégias de intervenção, cuidado, prevenção e enfrentamento mais efetivas. ${ }^{10}$

Ao reconhecer o processo que envolve a questão da violência, a possibilidade de denúncia da situação vivida, a procura dos serviços de apoio a esta mulher, a posição de persistir na relação ou de romper com esta convivência, observase que a mulher vive compartilhando o seu mundo com seu 
companheiro em uma atitude natural. Buscou-se, assim, compreender esta mulher, a partir dos significados que atribui às suas ações, atos, posições, decisões e relações. Nesse sentido, o presente artigo constitui um olhar de parte dos resultados da pesquisa de dissertação intitulada "Perspectivas de mulheres que denunciam o vivido da violência: cuidado de Enfermagem à luz de Alfred Schutz" e tem como objetivo apresentar perspectivas para o cuidado de enfermagem, a partir da apreensão do significado da ação das mulheres que denunciam o vivido da violência.

Entende-se que apreender o fenômeno da violência contra as mulheres sob uma dimensão que considera a mulher sujeito de sua história, buscando a compreensão do significado de sua ação e das relações por ela estabelecida a partir das vivências, constitui um importante subsídio para ação junto ao cliente. Possibilita-se, assim, a construção de um cuidado de enfermagem voltado à mulher a partir de suas necessidades $\mathrm{e}$ demandas sociais, e se reconhece que as necessidades assistenciais a esta população estão relacionadas ao seu mundo da vida.

\section{MÉTODO}

Estudo qualitativo, delineado pela linha teórica metodológica da Fenomenologia Social de Alfred Schütz. Para compreender a ação humana Schütz propõe apreender os motivos da ação. Conceitualmente 'motivo' refere-se ao "estado de coisas, o fim, em função do qual a ação foi levada a cabo". 11:124

Entende-se que as mulheres que realizam a denúncia podem descrever, com suas próprias palavras, a partir do mundo da vida cotidiana, de sua bagagem de conhecimentos e situação biográfica, os sentimentos e significados vivenciados, revelando a importância deste estudo para desvelar o vivido pelo sujeito, ir ao encontro do fenômeno como percebido em sua consciência. Desse modo, a expressão das mulheres que vivenciam cotidianamente tal situação permite compreender, em sua subjetividade, a forma como percebem a denúncia e o vivido desta violência.

Após a aprovação do projeto de pesquisa pelo Comitê de Ética em Pesquisa da Universidade Federal de Santa Maria ( No 23081.015518/2009-66.), desenvolveu-se a etapa de campo, que se cumpriu com a proteção dos sujeitos quanto aos princípios de: voluntariedade, consentimento livre e esclarecido, anonimato (identificadas por pseudônimos de flores, conforme concordância das participantes), confidencialidade das informações da pesquisa, justiça, equidade, diminuição dos riscos e potencialização dos benefícios, resguardando sua integridade física-mental-social de danos temporários e permanentes.

As participantes do estudo foram mulheres em situação de violência que realizam a denúncia da violência do companheiro em um órgão especializado no atendimento às vítimas de violência. Foram entrevistadas 13 mulheres, na faixa etária de 18 a 59 anos, que realizaram o registro da violência na Delegacia de Polícia para a Mulher (DPPM) e Delegacia de Pronto Atendimento (DPPA) de um município do interior do Rio Grande do Sul (RS), Brasil. As entrevistas foram desenvolvidas nas referidas delegacias, em sala disponibilizada pelo serviço que possibilitava privacidade. A seleção das mulheres deu-se de forma aleatória, mediante sua aceitação e disponibilidade em participar da pesquisa após a denúncia. 0 número de participantes não foi predeterminado, visto que a etapa de campo, desenvolvida concomitante à análise, mostrou o quantitativo de entrevistas necessário para responder ao objetivo da pesquisa, ao apontar a suficiência de significados expressos nas falas das mulheres. ${ }^{12}$

Ao buscar o motivo da ação da mulher que realiza a denúncia da violência, foi utilizada a entrevista fenomenológica. Para Schütz a pessoa explicita seu motivo, sua intencionalidade, por meio da comunicação. ${ }^{13}$ Essa entrevista oportuniza o sujeito a relatar sua vivência refere à questão, qual seja, o significado de sua ação. A produção dos dados ocorreu nos meses de março e abril de 2010, tendo por diretriz um roteiro de entrevistas contemplando a situação bibliográfica da entrevistada e a questão orientadora: o que você tem em vista quando realiza a denuncia da violência?

Para a análise das falas, foram desenvolvidos os seguintes passos: transcrição das entrevistas; leitura e releitura do conteúdo de cada entrevista; agrupamento por afinidade; captação dos "motivos para" em que foi feito um recorte das respostas à questão central.

Os "motivos para" referem-se a algo que se quer realizar, objetivos que busca alcançar, indicando uma estrutura temporal para o futuro, formando uma categoria subjetiva da ação, isto é, estreitamente relacionados com a ação e consciência do ator. ${ }^{11}$ Sendo assim, os motivos para, neste estudo, expressam a intenção das mulheres na ação de denunciar o companheiro pela violência vivida em uma delegacia.

Uma vez identificadas as ideias comuns refletidas nesses recortes, cada entrevista era lida e relida na íntegra, a fim de confirmar que essas ideias (categorias concretas do vivido) expressavam ao longo das falas dos sujeitos. ${ }^{14}$ Por fim, buscou-se, por meio das leituras das falas, identificar a relação das categorias entre si, chegando assim ao típico da ação das mulheres que realizam a denúncia, aquilo que representa a essência, o que é comum a esse grupo social. Os resultados foram interpretados e apoiados em concepções teóricas da Fenomenologia Social de Alfred Schütz. ${ }^{11,13}$

Visando atender o objetivo proposto para este artigo, são apresentadas perspectivas para um cuidado em enfermagem às mulheres em situação de violência construída a partir da intencionalidade e expectativas reveladas nas falas das participantes, que diz respeito às suas necessidades no contexto vivencial da violência. 


\section{RESULTADOS}

A partir da análise das falas, tem-se a apreensão do típico da ação: as mulheres, ao vivenciarem a ação de denunciar a violência cometida por seu companheiro, esperam acabar com a situação de violência que elas não aceitam e não aguentam mais.

A relação no início era bom, agora de dois anos pra cá ele sai [...] fica na rua, volta bêbado, drogado [...] Ele me ofende muito, me chama de vagabunda[...] Faz dias que assim, eu estou aguentando, e ele duvida [...] quero que ele não me incomode mais! (Orquídea)

Eu aceitava, agora eu não aceito mais [...]E a denúncia tem que dar, porque não tem mais convívio. Não consigo ficar perto dele, não consigo! Ele não vai me incomodar, como me incomodava! (Copo de leite)

Desejam ter paz e poder retomar seus planos e sua vida, com intenção de separar do companheiro.

Não respeita o meu emprego, porque eu tenho direito de trabalhar, de dormir, de estar em paz, sabe! Nem isso não tenho mais, paz! (Rosa)

Que me deixe livre! [...] quero estudar e ele não deixa! (Amaralis)

Eu não durmo de noite, não tenho mais paz! [...] Porque tu não sabe se vai acordar viva! Não sabe se tu vai se alimentar naquele dia, se vail leva um soco na cara, né! (chora). Já se levanta sendo espancada! (Violeta)

Conviver com ele não quero mais! Quero que as coisas se resolvam! um pra cada lado! Eu vivendo a minha vida com minha filha e ele longe! [...] só quero que a gente se separe. (Lisianthus)

Não vou mentir que eu não goste dele, estou decepcionada, magoada, triste, mas a separação é inevitável pela minha saúde e minha filha! (Gérbera)

Eu quero me separar dele! [...] Se a nossa vida não foi boa até agora, não vai adiantar eu continuar com ele!(Tulipa)

Têm expectativas com relação à necessidade de justiça e de proteção sua e de seus filhos.
Vieira LB, Padoin SMM, Souza IEO, Paula CC

Espero que alguma coisa seja feita dessa vez! [...] Ele tem que pagar! Eu espero que dessa vez prendam ele [...] (Rosa)

Meu objetivo com esta ocorrência é que ele me respeitasse, como ser humano. 0 que me criou coragem (denúncia) foi o fato de meu filho ter assistido (violência), daí eu tive vergonha de mim mesma e não ficar com os braços cruzados! (Boca de leão)

Espero que haja justiça, pra ter um pouco de paz! Por isso que eu estou aquil! Eu não vô deixar impune, eu quero tocar pra frente! Tô aqui por causa dos meus filhos [...] eu preciso proteger eles(Girassol)

Espero hoje sair daqui com ao menos nós vamos te ajudar a viver melhor! [...] E tirem ele de perto de mim pra eu poder viver! (Gérbera)

\section{DISCUSSÃO}

Significando uma relação de anonimato com 0 companheiro e buscando construir relações de familiaridade para enfrentamento da violência

A intencionalidade da mulher ao denunciar o vivido da violência em uma delegacia especializada está apoiada na possibilidade de acabar com a situação relacional estabelecida com o companheiro que não aceita e aguenta mais. Tal motivo expressa a não aceitação de uma relação que diz estar insuportável, que representa para si um incômodo, sem, nesse momento, a possibilidade de retomar a relação conjugal.

Aponta-se que a mulher, ao significar sua motivação em denunciar a violência vivida, deseja estabelecer um afastamento, revelando uma relação de anonimato com seu companheiro.

0 mundo da vida é experimentado por nós, segundo graus de familiaridade e de anonimato. A relação de familiaridade é vivida sob a forma do nós e permite a apreensão do outro como único em sua individualidade. ${ }^{11}$ Nesse sentido, a relação de anonimato da mulher e seu companheiro se estabelece, uma vez que já não há com este uma relação de familiaridade, sob a forma de nós. Quanto mais anônima for a relação, tanto mais afastada estará a unicidade e a individualidade de meu semelhante e pouquíssimos aspectos serão considerados como relevantes para o problema que desejo tratar ou resolver.

A mulher expressa que a ação de denunciar o companheiro pela agressão vivida perpassa pela decisão de romper com costumes e hábitos que não aceita mais e que Ihe causam sofrimento.

A intersubjetividade é a categoria fundamental da existência humana no mundo, uma vez que é na relação de intersubjetividade do nós, que o mundo circundante nos é comum 
e com ele coincidimos, ao menos para as nossas necessidade práticas, para que possamos partilhar nossas experiências. É justamente nessa relação que emergem os desafios. ${ }^{11}$

É neste mundo intersubjetivo, compartilhado com seus semelhantes, que a mulher está inserida, em um compartilhar contínuo de experiências, interação e comunicação. Uma das formas de superar os problemas que afetam a intersubjetividade é por meio do intercâmbio de pontos de vista. Para isso, se faz necessário reconhecer que cada sujeito ocupa determinado lugar na sociedade. A idealização de acordos ou a realização de congruência dos sistemas de relações busca resgatar o caráter intersubjetivo. ${ }^{11}$

Apreende-se que, na relação intersubjetiva com 0 companheiro, há carência de intercâmbios de pontos de vista, alegando que esse fere seus direitos como pessoa e, por vezes, não a respeita. A mulher na sua ação intencional de não mais relacionar-se com o companheiro, a partir do projeto/motivo de separar-se dele, espera não mais estabelecer uma relação face a face com este e deseja não mais compartilhar um tempo e um espaço comum, uma vez que a relação de familiaridade, permeada de confiança, amizade e amor já não se estabelece, conduzindo para o anonimato. ${ }^{11}$

A intenção da mulher, ao denunciar, envolve a necessidade de proteção por meio da justiça. Expressa a necessidade de acreditar na justiça, espera providências em relação a sua situação. Reconhece a Lei Maria da Penha como um instrumento mediador de justiça, esperando do serviço policial e judiciário a proteção e ajuda de que necessita. Entretanto, aponta as incertezas e dúvidas no que diz respeito aos desfechos da lei.

0 intercâmbio de pontos de vista e o acordo prático dos sistemas de escolhas, constituem a tese geral da reciprocidade de perspectivas. A "tese geral pressupõe objetivos em comum, a intersubjetividade e a comunicação, conduzindo a apreensão de objetos conhecidos por mim e conhecíveis pelos outros". ${ }^{15: 34}$ Ao analisar o projeto almejado pela mulher, ao realizar a denúncia, vislumbram-se as expectativas em relação ao cumprimento da lei de forma efetiva, garantindo a esta a proteção de que necessita.

Entretanto, ao nos reportarmos aos serviços que prestam atendimento às mulheres em situação de violência e, em especial à delegacia, cenário deste estudo, encontramos lacunas. A incerteza quanto à resolubilidade da lei e questionamentos sobre sua real proteção apontam para a falta de intercâmbio de pontos de vista, entre mulher e profissionais que prestam atendimento na delegacia. 0 "motivo para" da mulher e o "motivo porque" dos profissionais que prestam atendimento apontam para um déficit de intersubjetividade e comunicação entre esses, e carência de relações de familiaridade tão almejada pelas mulheres nesta situação, de modo que não se efetiva reciprocidade de perspectivas.

Cabe ressaltar que os profissionais que prestam atendimento às mulheres em situação de violência, com destaque a enfermagem, devem considerar a sua situação biográfica determinada: a situação de ser uma mulher, membro de uma relação que convive com o companheiro agressor; biográfica, no sentido de ter uma experiência e a vida cotidiana marcada pelo convívio com a violência; e determinada, como uma situação habitual e em constante repetição, de modo que a violência constitui-se como uma situação que se faz habitual em um corpo que é instrumento sinalizador - é nele que estão as marcas do seu modo de viver humano. A vivência de violência expressa um cotidiano imerso em conflitos constantes.

A intenção da denúncia revela a necessidade de proteger e criar seu(s) filho(s) livre(s) da violência por eles assistida e, por vezes, vivenciada. Revela sua angústia no que diz respeito a estar viva para poder cuidar do(s) filho(s), uma vez que o companheiro ameaça tirar sua vida. Assim, faz-se importante apreender suas angústias, que "deve ser considerada, pois os tipos sociais não se fixam, dando margem para a liberdade e para o imponderável". 15:87 Manter-se viva pata cuidar de seu(s) filho(s), apesar das agressões sofridas, é uma angústia das mulheres deste estudo.

Tem-se, portanto, uma faceta desvelada da intencionalidade das mulheres que denunciam o vivido da violência em uma delegacia. Ao considerar o mundo da vida desta mulher, que é um mundo social, aponta-se que apreender os motivos que as levam a denunciar requer compreender as relações que a mulher estabelece, seja com o companheiro, seja com os filhos, familiares, com os profissionais que atendem esta demanda, ou seja, compreender sua rede social. Implica ampliar o olhar sobre o fenômeno da violência, não o restringindo a aspectos biológicos, das clássicas intervenções físicas no setor saúde e no cuidado de enfermagem. É imprescindível transcender para aspectos históricos, sociais, culturais, relacionais, econômicos, éticos e jurídicos para com isso buscar estabelecer relações de familiaridade e intersubjetividade com este segmento.

\section{CONSIDERACÕES FINAIS}

A busca do significado da ação de denunciar, por meio da apreensão de suas motivações, permitiu um olhar para a mulher no seu singular e social. Essa se sentiu olhada, demonstrando interesse em falar de sua vida, suas relações, seus conflitos e angústias. Revelou-se que a mulher, ao procurar ajuda em um serviço, espera falar, ser ouvida e, principalmente, compreendida, muito mais do que ouvir conceitos e pontos de vistas preestabelecidos, como: "por que você não se separa?", "por que você ainda não denunciou?", "você pediu para apanhar", "essa mulher está sempre aqui com esta queixa", "você está doente", entre outros. 
Por vezes, o contexto social do problema e todo o movimento de desnaturalização e desconstrução social de comportamentos ainda aceitos não são contemplados na prestação de cuidado a essa clientela, indo de encontro ao que apregoam as políticas públicas. Demonstra-se, assim, que os profissionais constituintes da rede de assistência às mulheres em situação de violência, na maioria das vezes não apresentam atitude de escuta quando realizam o atendimento. Sem considerar o contexto vivencial da mulher, estabelecem uma relação anônima, detendo-se na queixa pontual da situação de violência.
A relação da enfermagem e da mulher em situação de violência, se sistematizada nos cenários possíveis de sua assistência, como na unidade de saúde, na escola, na unidade de internação hospitalar, no pronto atendimento, no domicílio, na comunidade, na delegacia e tantos outros, possibilitará, verdadeiramente, a construção do relacionamento de familiaridade do tipo eu-tu e eu-nós. Dessa forma, o enfermeiro escuta o significado objetivo trazido pelas mulheres permeado de subjetividade e intencionalidades, de forma que se relaciona com essas mulheres e constrói possibilidades de cuidado de maneira conjunta e recíproca, considerando-a como sujeito de sua história (Figura 1).

\section{MUNDO DA VIDA}

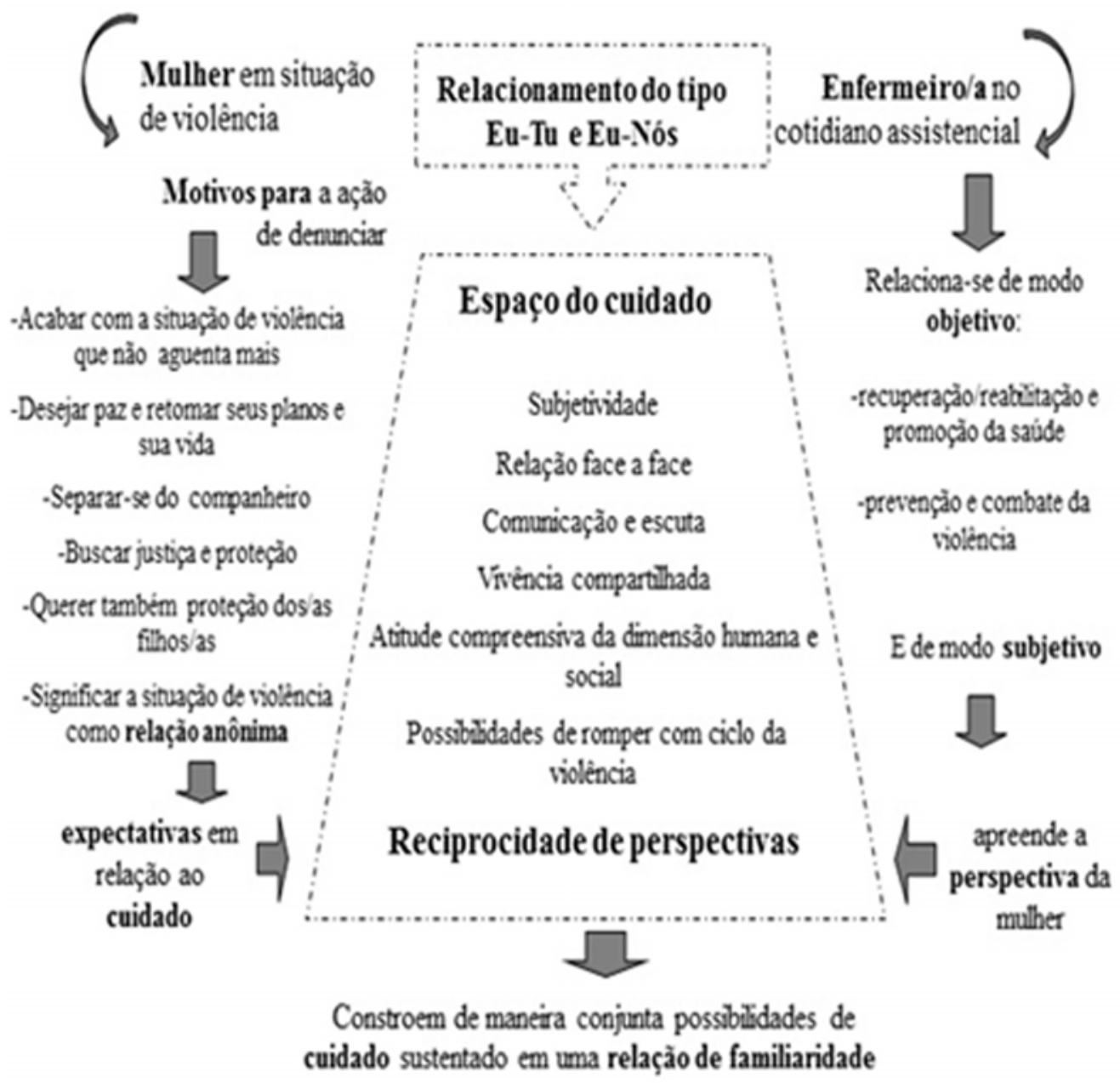

Figura 1 - Possibỉdade, à huz de Schütz, do Cuidado de Enfermagem às Muheres em Sítuação de Violencia. 
0 setor saúde é parte integrante da rede de atenção a mulheres em situação de violência, e configurase, na maioria das vezes, como a porta de acesso das mulheres nesta rede, na busca de cuidados. Neste cenário, a enfermagem desempenha papel fundamental no reconhecimento, acolhimento, prevenção e intervenção nas consequências geradas pela violência. Dessa forma, a ação assistencial do enfermeiro para as mulheres deve ser voltada às suas necessidades assistenciais que estão relacionadas com seu mundo da vida, centrados no sujeito, a partir dela própria.

A enfermagem, ao desempenhar sua ação profissional junto à mulher em situação de violência, ao considerar seu mundo da vida, deve direcionar suas ações de cuidado com vistas a estabelecer uma relação face a face com a mulher, permeada pela subjetividade, apreendendo o outro de uma maneira mais viva e direta, vivenciando-a de forma imediata, a partir de sua realidade, almejando uma relação de familiaridade com esta. Fazse, portanto, necessário que o profissional tenha uma postura realista, ética e solidária considerando a totalidade dos condicionantes envolvidos com a violência, indo ao encontro da mulher por meio de sua vivência compartilhada.

0 espaço de cuidado entre mulher-enfermagem deve ser permeado pela comunicação, em que as expectativas da mulher em relação à assistência sejam alcançadas. Há a necessidade de compreender a violência não apenas no seu aspecto biológico, e os profissionais não como meros intervencionistas nas queixas físicas, mas como agentes de promoção e prevenção da saúde, constituintes de uma rede de serviços que buscam combater, cada um em sua instância, as sequelas e disseminação de uma cultura de violência.

Faz-se relevante mencionar que tais apontamentos vão ao encontro do preconizado pela Política Nacional de Humanização que possui, entre seus princípios básicos, a valorização da dimensão subjetiva e social, em todas as práticas de atenção e gestão no Sistema Único de Saúde, destacando o respeito às questões de gênero, etnia, raça, orientação sexual e também 0 respeito às populações específicas e à construção de autonomia e protagonismo dos sujeitos e coletivos implicados nesta rede.

Sendo assim, a investigação pautada neste alicerce teórico permitiu construir um impor tante subsídio para ação do profissional, em especial de enfermagem, junto ao cliente, que aborda questões vividas no mundo social, mundo este que atua e interage. A enfermagem, em sua prática cotidiana de cuidado nos diferentes serviços de saúde, deve buscar orientar e conduzir a mulher para que a sua necessidade de justiça seja atendida, através de uma assistência que esteja integrada a outros serviços de forma intersetorial, e desenvolvendo os encaminhamentos necessários, fundamentados na legislação que coíbe a violência, no sentido de respaldar esta mulher legalmente.

Portanto, este estudo da vivência da mulher que denuncia à violência, na perspectiva fenomenológica, desvelou uma faceta da realidade social deste grupo, ampliando a visão acerca dos determinantes socioculturais envolvidos no fenômeno.

Nesse sentido, a contribuição do pensamento de Schütz para a enfermagem diz respeito a compreender o outro - a mulher em situação de violência - na sua dimensão humana e social no mundo da vida, e possibilita, assim, pensar, projetar e agir por meio de ações assistenciais que condizem com as necessidades e contexto vivencial desta clientela.

Ressalta-se a importância de se realizarem estudos que se aproximem do contexto vivencial das mulheres, no seu mundo da vida cotidiana, a partir de uma abordagem compreensiva, que considera o ser humano em sua totalidade existencial e inserido em uma sociedade histórica e culturalmente situada, e não apenas no sentido biológico.

\section{REFERÊNCIAS}

1-Minayo MCS. The difficult and slow inclusion ofviolence on the health sector agenda. Cad Saude Publica 2004 maio/jun; 20(3): 646-47.

2-Jong LC, Sadala MLA, Tanaka ACDA. Desistindo dadenuncia ao agressor: relato de mulheres vítimas deviolência doméstica. Rev Esc Enferm USP. 2008; 42(4) :744-51.

3-Souza ML, Sartor VVB, Padilha MICS, Prado ML. 0 cuidado em enfermagem - uma aproximação teórica. Texto\&Contexto Enferm. 2005; 14(2): 266-70.

4-Carneiro AD, Costa SFG, Pequeno MJP. Disseminação de valores éticos no ensino do cuidar em Enfermagem: estudo fenomenológico. Texto\&Contexto Enferm. 2009; 18(4): 722-30.

5-Carvalho V. Cuidando, pesquisando e ensinando: acerca de significados e implicações da prática da enfermagem. Rev Latino-am Enfermagem. 2004; 12(5): 806-15.

6-Corrêa MSM, Lopes RLM, Diniz NMF. Reflexões sobre o cuidar de mulheres que sofrem violência conjugal em uma perspectiva heideggeriana do mundo da técnica. Rev Esc Enferm USP. 2001; 35(3): 230-34.

7-Guedes RN, Silva ATMC, Fonseca RMGS. A violência de gênero e o processo saúde-doença das mulheres. Esc Anna Nery. 2009; 13 (3): 625-31.

8-Ministério da Saúde (BR), Secretaria de Atenção à Saúde. Departamento de Ações Programáticas Estratégicas. Política Nacional de Atenção Integral à Saúde da Mulher: princípios e diretrizes. Brasília (DF); 2007. 
9-Lei Maria da Penha. Lei n 11.340, de 07 de agosto de 2006. Coíbe a violência doméstica e familiar contra a mulher. Brasília (DF): Secretaria Especial de Políticas para as Mulheres; 2006.

10-Miranda MPM, Paula CS, Bordin IA. Violência conjugal física contra a mulher na vida: prevalência e impacto imediato na saúde, trabalho e família. Rev Panam Salud Publica. 2010; 27(4): 300-38.

11-Schütz A. Fenomenologia e relações sociais. Rio de Janeiro: Zahar; 1979.

12-Boemer M.R. A condução de estudos segundo a metodologia de investigação fenomenológica. Rev Latino-am Enfermagem. 1994; 2(1): 69-82.

13-Schütz A. Fenomenologia del mundo social: introduçción a la Sociologia Compreensiva. Buenos Aires: Ed Paidos; 1972.

14-Tocantins FR. As necessidades na relação cliente-enfermeiro em uma unidade básica de saúde: uma abordagem na perspectiva de Alfred Schütz [tese]. Rio de Janeiro Escola de Enfermagem Anna Nery, Universidade Federal do Rio de Janeiro; 1993.

15-Capalbo C. Metodologia das ciências sociais: a fenomenologia de Alfred Schütz. Londrina: Ed. UEL; 1998. 